Article

\title{
Applications of Poly(indole-6-carboxylic acid-co-2,2'-bithiophene) Films in High-Contrast Electrochromic Devices
}

\author{
Chung-Wen Kuo ${ }^{1}$, Tzi-Yi Wu ${ }^{2, *}$ (D) and Shu-Chien Fan ${ }^{1}$ \\ 1 Department of Chemical and Materials Engineering, National Kaohsiung University of Science and Technology, \\ Kaohsiung 80778, Taiwan; welly@cc.kuas.edu.tw (C.-W.K.); zjan70255@gmail.com (S.-C.F.) \\ 2 Department of Chemical Engineering and Materials Engineering, \\ National Yunlin University of Science and Technology, Yunlin 64002, Taiwan \\ * Correspondence: wuty@gemail.yuntech.edu.tw; Tel.: +886-5-534-2601 (ext. 4626)
}

Received: 14 February 2018; Accepted: 9 March 2018; Published: 13 March 2018

\begin{abstract}
Two homopolymers (poly(indole-6-carboxylic acid) (PInc) and poly(2,2'-bithiophene) $(\mathrm{PbT}))$ and a copolymer (poly(indole-6-carboxylic acid-co-2,2'-bithiophene) (P(Inc-co-bT))) are electrodeposited on ITO electrode surfaces via electrochemical method. Electrochemical and electrochromic properties of PInc, $\mathrm{PbT}$, and $\mathrm{P}(\mathrm{Inc}-\mathrm{co}-\mathrm{bT})$ films were characterized using cyclic voltammetry and in situ UV-Vis spectroscopy. The anodic $\mathrm{P}$ (Inc-co-bT) film prepared using Inc. $/ \mathrm{bT}=1 / 1$ feed molar ratio shows high optical contrast $(30 \%$ at $890 \mathrm{~nm})$ and coloring efficiency $\left(112 \mathrm{~cm}^{2} \mathrm{C}^{-1}\right.$ at $\left.890 \mathrm{~nm}\right) . \mathrm{P}($ Inc-co-bT) film revealed light yellow, yellowish green, and bluish grey in the neutral, intermediate, and oxidation states, respectively. Electrochromic devices (ECDs) were constructed using PInc, $\mathrm{PbT}$, or $\mathrm{P}(\mathrm{Inc}-\mathrm{co}-\mathrm{bT})$ film as anodic layer and PEDOT-PSS as cathodic layer. P(Inc-co-bT)/PMMA-PC-ACN-LiClO 4 /PEDOT-PSS ECD showed high $\Delta T(31 \%)$ at $650 \mathrm{~nm}$, and PInc/PMMA-PC-ACN-LiClO 4 /PEDOT-PSS ECD displayed high coloration efficiency $\left(416.7 \mathrm{~cm}^{2} \mathrm{C}^{-1}\right)$ at $650 \mathrm{~nm}$. The optical memory investigations of PInc/PMMA-PC-ACN-LiClO 4 /PEDOT-PSS, PbT/PMMA-PC-ACN-LiClO 4 /PEDOT-PSS, and $\mathrm{P}(\mathrm{Inc}-\mathrm{co}-\mathrm{bT}) / \mathrm{PMMA}-\mathrm{PC}-\mathrm{ACN}-\mathrm{LiClO}_{4} / \mathrm{PEDOT}-\mathrm{PSS}$ ECDs exhibited that ECDs had adequate optical memory in bleaching and coloring states.
\end{abstract}

Keywords: electrochromic device; electrodeposition; anodic polymer layer; spectroelectrochemistry; electrochromic switching; coloration efficiency

\section{Introduction}

Conjugated polymers have sparked enormous attention for applications in solar energy conversion [1,2], electrochromic devices (ECDs) [3-5], chemical sensing materials [6,7], catalysts for methanol oxidation in direct methanol fuel cells [8-10], and polymer organic light emitting diodes (polymer OLEDs, or PLEDs) [11-13] due to their intriguing optical, electrochemical, and structural properties. Among them, the applications of conjugated polymers in developing high contrast electrochromic devices are currently attractive due to their energy-saving and light control properties. During the last decade, the most frequently studied electrochromic polymers are polythiophenes [14,15], polycarbazoles [16,17], polyindoles [18], polyanilines [19], polytriphenylamine [20], and polypyrroles [21]. Among them, polyindoles have several benefits such as high conductivity, facile polymerization from organic or aqueous media, and good chemical stability. Moreover, polyindoles show higher thermal stability and redox activity than those of polypyrroles and polyanilines. Polythiophenes and their derivatives also show good stability toward moisture and oxygen in their oxidized and reduced states, they can be functionalized by the incorporations of oxygen and sulfur atoms at 3,4-postions 
of the thiophene unit, and the absorption spectra and electrochemical onset potential can be tuned for functionalized polythiophenes. In addition, copolymerization of diverse monomers containing numerous distinct components can bring about intriguing results of the electrochromic behaviors observed in their corresponding homopolymer films [22]. For the affair, a copolymer contains indole and thiophene derivatives were prepared electrochemically to explore the intriguing properties.

The purpose of this study is to prepare $\mathrm{P}(\mathrm{Inc}-\mathrm{co}-\mathrm{bT})$ film using electrochemical polymerization and compare its spectroelectrochemical properties, multicolored behaviors, transmittance variations, and coloration efficiency with its corresponding homopolymers (PInc and $\mathrm{PbT}$ films). Moreover, ECDs were fabricated using PInc, $\mathrm{PbT}$, and $\mathrm{P}(\mathrm{Inc}-\mathrm{co}-\mathrm{bT})$ films as the anodic materials, PEDOT-PSS as the cathodic material and a PMMA-PC-ACN-LiClO 4 composite film as the electrochromic electrolyte. The electrochromic behavior, spectroelectrochemistry, coloration efficiency, optical memory effect, and redox stability of PInc/PMMA-PC-ACN-LiClO 4 /PEDOT-PSS, P(Inc-co-bT)/PMMA-PC-ACN-LiClO ${ }_{4} /$ PEDOT-PSS, and PbT/PMMA-PC-ACN-LiClO 4 /PEDOT-PSS ECDs were explored in detail.

\section{Materials and Methods}

\subsection{Materials}

Indole-6-carboxylic acid and 2,2'-bithiophene were purchased from Aldrich and TCI, respectively, and used as received. Poly(3,4-ethylenedioxythiophene)-poly(styrenesulfonate) (PEDOT-PSS) $1.3 \mathrm{wt} \%$ dispersion in $\mathrm{H}_{2} \mathrm{O}$ was purchased from Aldrich (St. Louis, MO, USA). PInc, PbT, and $\mathrm{P}$ (Inc-co-bT) films were electrodeposited potentiostatically at $+1.0 \mathrm{~V}$ on ITO glass with a charge density of $50 \mathrm{mC} \mathrm{cm} \mathrm{cm}^{-2}$, the feed species and feed molar ratio of PInc, PbT, and $\mathrm{P}(\mathrm{Inc}-\mathrm{co}-\mathrm{bT})$ films were displayed in Table 1. The composite electrolyte for electrochromic characterization was prepared using a mixture solution of PMMA, $\mathrm{LiClO}_{4}, \mathrm{PC}$, and ACN according to previously published work [23].

Table 1. Feed species of anodic polymer electrodes (a)-(c).

\begin{tabular}{cccc}
\hline Electrodes & Anodic Polymers & Feed Species of Anodic Polymer & Feed Molar Ratio of Anodic Polymer \\
\hline (a) & PInc & $4 \mathrm{mM}$ Inc. & Neat Inc. \\
(b) & $\mathrm{P}($ Inc-co-bT) & $4 \mathrm{mM} \mathrm{Inc.}+4 \mathrm{mM} \mathrm{bT}$ & $1: 1$ \\
(c) & $\mathrm{PbT}$ & $4 \mathrm{mM} \mathrm{bT}$ & Neat bT \\
\hline
\end{tabular}

\subsection{Electrochemical and Spectroelectrochemical Characterizations}

The electrochemical and spectroelectrochemical properties of PInc, PbT and P(Inc-co-bT) films coated on ITO electrodes and PInc/PMMA-PC-ACN-LiClO 4 /PEDOT-PSS, PbT/PMMA-PC-ACN-LiClO 4 / PEDOT-PSS, and P(Inc-co-bT)/ MMA-PC-ACN-LiClO 4 /PEDOT-PSS ECDs were investigated using a HITACHI UV-Visible spectrophotometer (Hitachi, Tokyo, Japan) and a CHI627D electrochemical analyzer ( $\mathrm{CH}$ Instruments, Austin, TX, USA). The active area of PInc, $\mathrm{PbT}$, and $\mathrm{P}($ Inc-co-bT) films on ITO electrodes was $1.0 \times 1.5 \mathrm{~cm}^{2}$. UV-Visible spectra of polymer films in $0.2 \mathrm{M}$ $\mathrm{LiClO}_{4} /(\mathrm{PC}+\mathrm{ACN})$ solution and ECDs were scanned with a rate of $500 \mathrm{~nm} \mathrm{~min}{ }^{-1}$. Electrochemical switching properties of PInc, $\mathrm{P}\left(\right.$ Inc-co-bT), and PbT films in $0.2 \mathrm{M} \mathrm{LiClO}_{4} /(\mathrm{PC}+\mathrm{ACN})$ solution were monitored between 0.0 and $+0.8 \mathrm{~V}$ (vs. $\mathrm{Ag} / \mathrm{AgNO}_{3}$ ) with a residence time of $10 \mathrm{~s}$. Open circuit stabilities of PInc/PMMA-PC-ACN-LiClO 4 /PEDOT-PSS, P(Inc-co-bT)/PMMA-PC-ACN-LiClO 4 / PEDOT-PSS, and PbT/PMMA-PC-ACN-LiClO 4 /PEDOT-PSS ECDs were monitored at 650, 650 and $690 \mathrm{~nm}$, respectively.

\subsection{Fabrication of ECDs}

ECDs were assembled using PInc, PbT, or P(Inc-co-bT) film as the anodic layer, PEDOT-PSS film as the cathodic layer and a PMMA-PC-ACN-LiClO 4 composite film as the electrochromic electrolyte. ECDs were fabricated by anodic and cathodic layers facing each other and were separated by a PMMA-PC-ACN-LiClO 4 composite film as shown in Figure 1. 


\section{PInc/PE DOT-PSS}

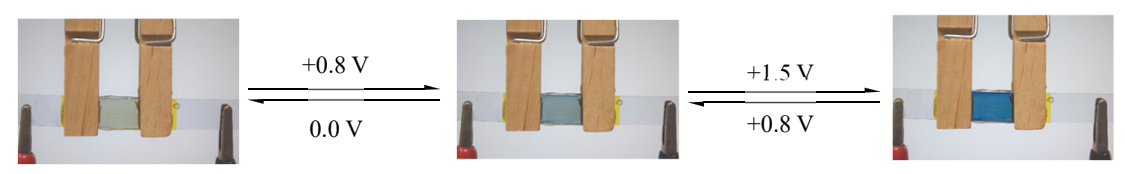

P(Inc-co-bT)/PEDOT-PSS
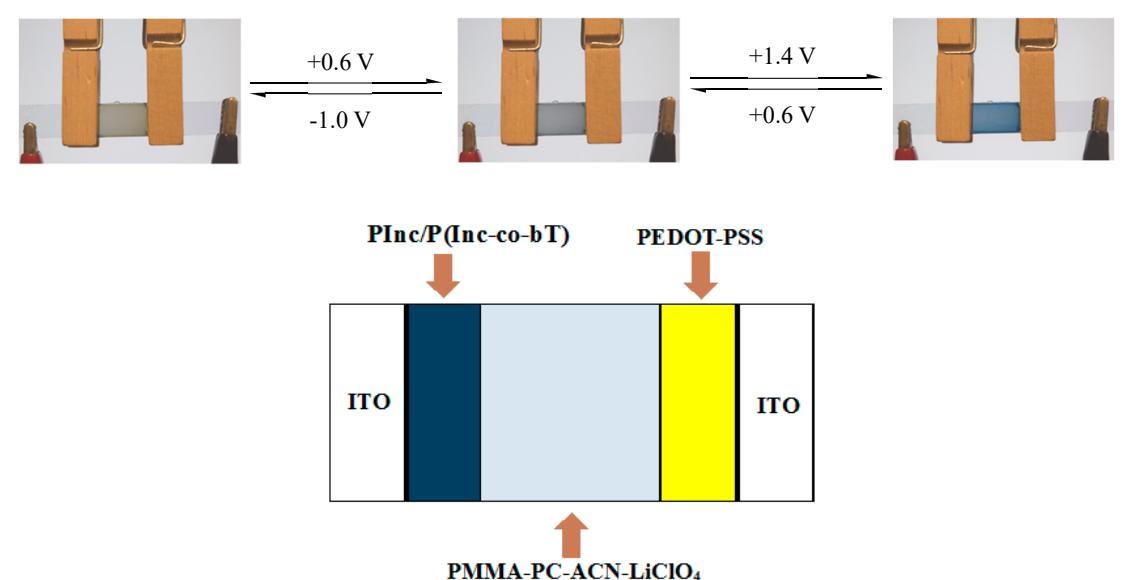

Figure 1. Schematic diagrams of PInc/PMMA-PC-ACN-LiClO 4 /PEDOT-PSS and P(Inc-co-bT)/PMMAPC-ACN-LiClO 4 /PEDOT-PSS devices.

\section{Results and Discussion}

\subsection{Electrochemical Polymerizations of PInc, PbT and P(Inc-co-bT) Films}

The anodic polarization curves of Inc., bT, and their mixture (Inc. + bT) in PC+ACN solution containing $0.2 \mathrm{M} \mathrm{LiClO}_{4}$ are shown in Figure 2, the onset potentials of Inc., bT, and their mixture (Inc. $+\mathrm{bT}$ ) are $0.64,0.81$, and $0.84 \mathrm{~V}$ vs. $\mathrm{Ag} / \mathrm{AgNO}_{3}$, respectively. The deviation of onset potentials between Inc. and bT is less than $0.2 \mathrm{~V}$, implying the feasibility of copolymerization using the two monomers.

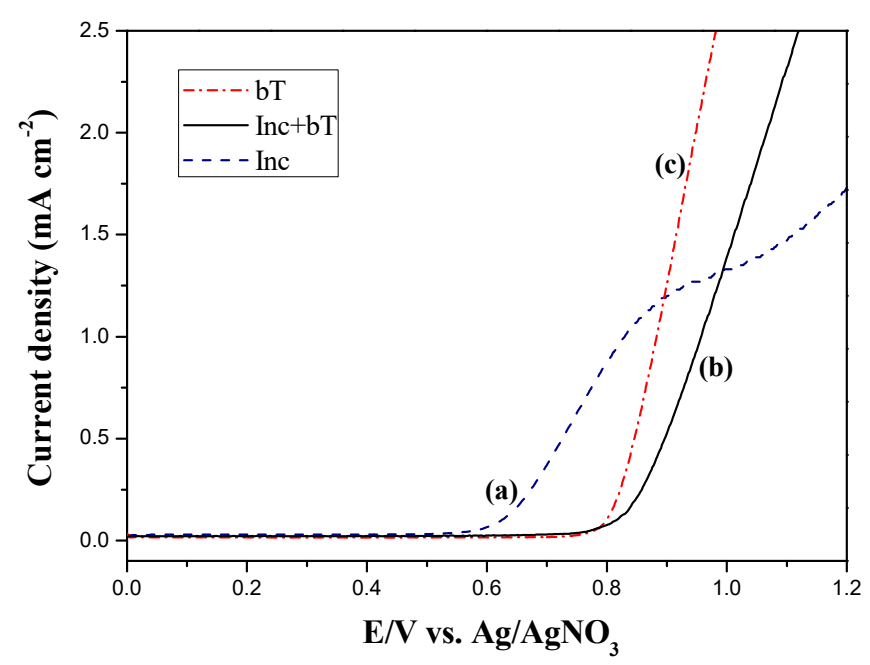

Figure 2. Anodic polarization curves of (a) $4 \mathrm{mM}$ Inc., (b) $4 \mathrm{mM}$ Inc. $+4 \mathrm{mM} \mathrm{bT}$, and (c) $4 \mathrm{mM}$ bT in $\mathrm{PC}+\mathrm{ACN}$ solution containing $0.2 \mathrm{M} \mathrm{LiClO}_{4}$ at a scan rate of $100 \mathrm{mV} \mathrm{s}^{-1}$. 
Figure 3 shows the repetitive cycling at potentials between 0.0 and $1.4 \mathrm{~V}$ for 8 cycles, the increased current density clearly indicated PInc, $\mathrm{P}(\mathrm{Inc}-\mathrm{co}-\mathrm{bT})$, and $\mathrm{PbT}$ films were electrodeposited onto ITO glass substrate during the repetitive cycling.
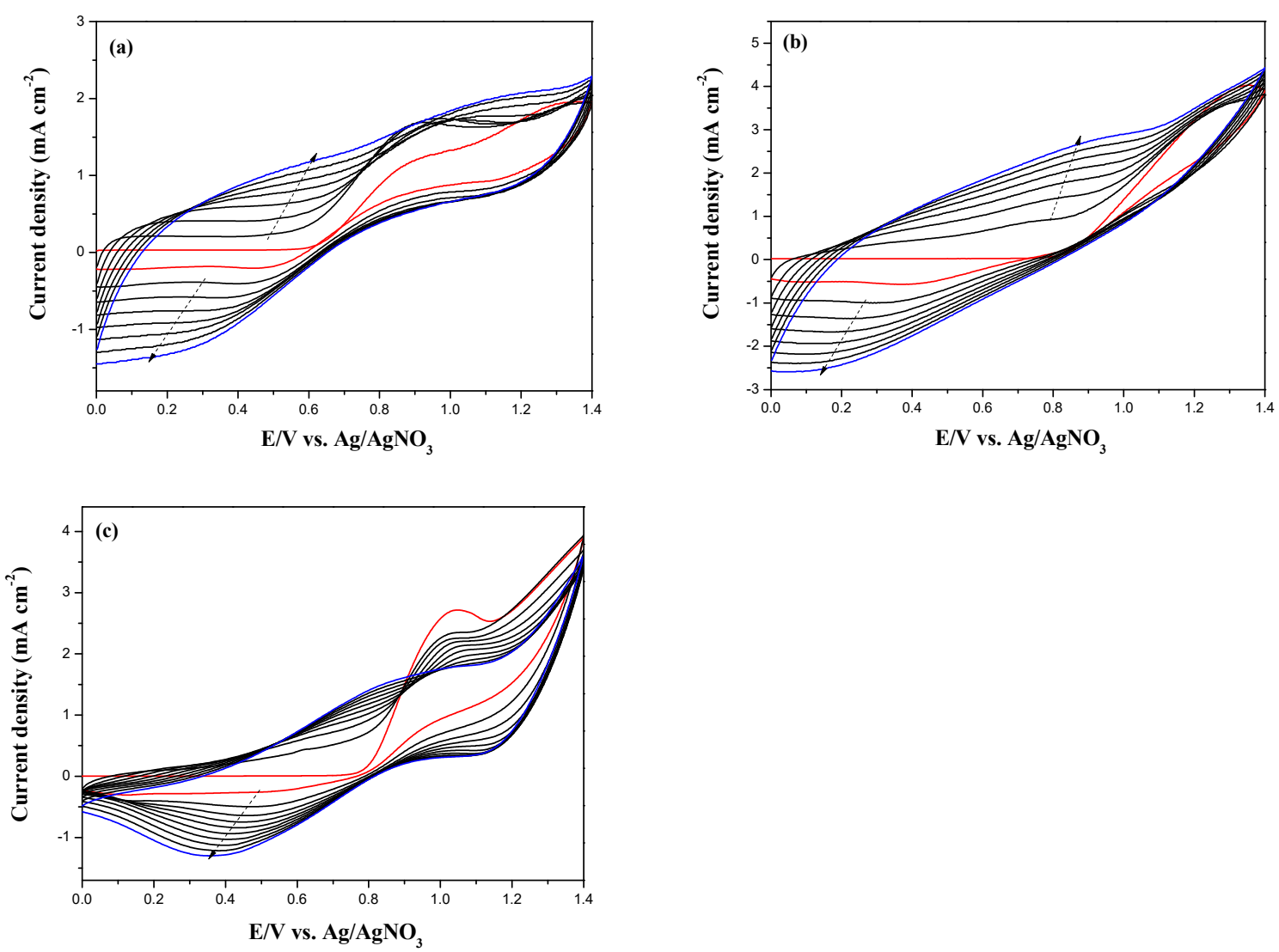

Figure 3. Electrochemical synthesis of (a) PInc, (b) P(Inc-co-bT), and (c) PbT in PC $+\mathrm{ACN}$ solution at $100 \mathrm{mV} \mathrm{s}^{-1}$ on ITO working electrodes.

Moreover, the oxidation peaks of PInc, P(Inc-co-bT), and PbT films located at 0.92, 1.26, and $1.05 \mathrm{~V}$, respectively, and the reduction peaks of PInc, $\mathrm{P}(\mathrm{Inc}-\mathrm{co}-\mathrm{bT})$, and $\mathrm{PbT}$ films located at $0.46,0.40$, and $0.44 \mathrm{~V}$, respectively. The redox peaks and wave shapes of $\mathrm{P}(\mathrm{Inc}-\mathrm{co}-\mathrm{bT})$ film are different to those of PInc and $\mathrm{PbT}$ films, demonstrating the formation of $\mathrm{P}(\mathrm{Inc}-\mathrm{co}-\mathrm{bT})$ film on ITO glass substrate. The electrosynthetic scheme of $\mathrm{P}(\mathrm{Inc}-\mathrm{co}-\mathrm{bT})$ is displayed in Figure $4[24,25]$.
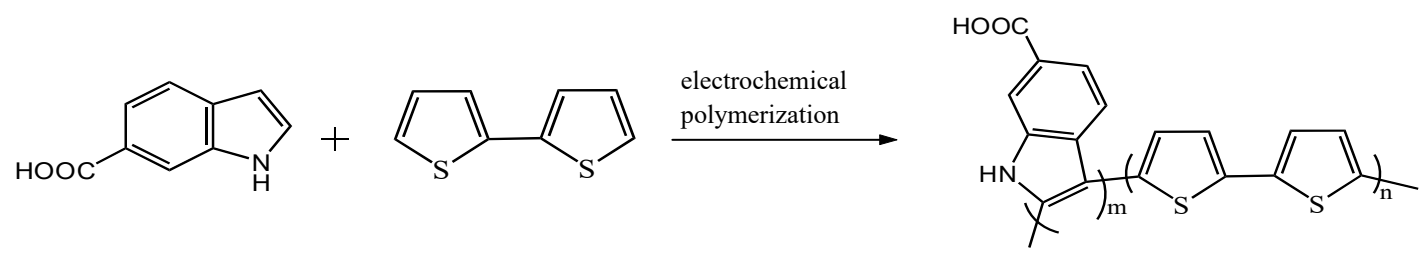

Figure 4. The electrochemical polymerization scheme of $\mathrm{P}(\mathrm{Inc}-\mathrm{co}-\mathrm{bT})$.

The redox behavior of $\mathrm{P}(\mathrm{Inc}-\mathrm{co}-\mathrm{bT})$ film was studied using cyclic voltammograms at scanning rates between 10 and $200 \mathrm{mV} \mathrm{s}^{-1}$ in $0.2 \mathrm{M} \mathrm{LiClO}_{4} /(\mathrm{PC}+\mathrm{ACN})$ solution, and the results are shown in Figure 5. 

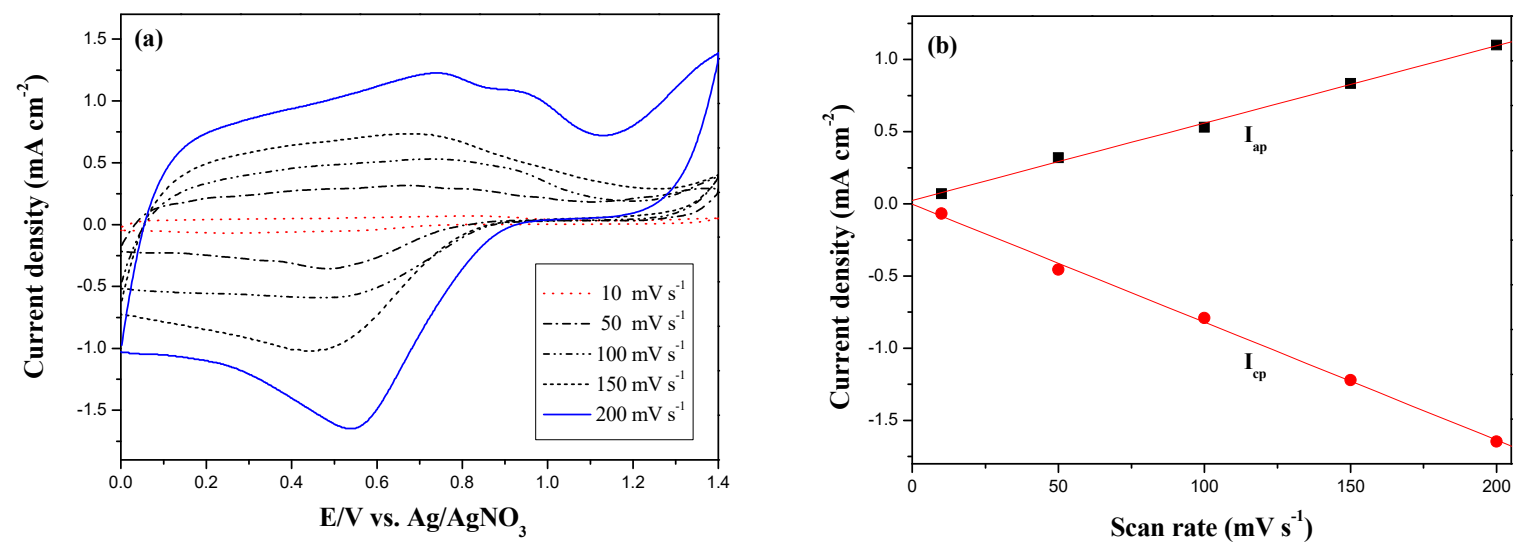

Figure 5. (a) CV curves of the $\mathrm{P}(\mathrm{Inc}-\mathrm{co}-\mathrm{bT})$ film at different scan rates between 10 and $200 \mathrm{mV} \mathrm{s}^{-1}$ in $\mathrm{PC}+\mathrm{ACN}$ solution containing $0.2 \mathrm{M} \mathrm{LiClO}_{4}$; (b) Scan rate dependence of the anodic and cathodic peak current densities of $\mathrm{P}($ Inc-co-bT) film.

The P(Inc-co-bT) films reveal a quasi-reversible oxidation-reduction couple, indicating the doping and de-doping processes of the $\mathrm{P}(\mathrm{Inc}-\mathrm{co}-\mathrm{bT})$ film, the redox behavior and polaron mechanism of $\mathrm{P}$ (Inc-co-bT) film is shown in Figure 6. As shown in Figure 5b, both anodic and cathodic peak current density increase linearly with increasing scan rate, representing P(Inc-co-bT) film was well adhered onto ITO surface and the oxidation and reduction processes of the polymer film was not diffusion controlled [26].
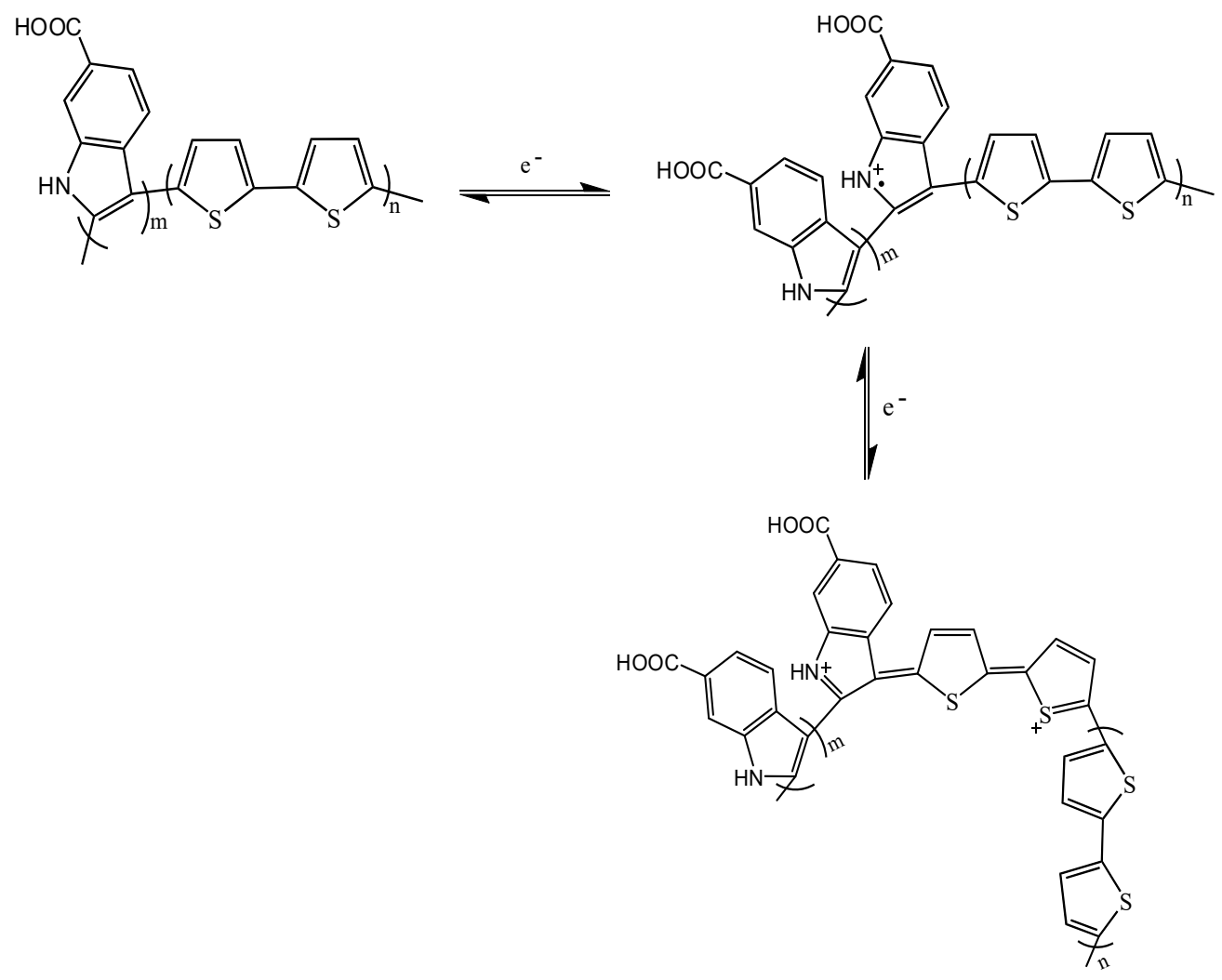

Figure 6. Redox behavior of the $\mathrm{P}(\mathrm{Inc}-\mathrm{co}-\mathrm{bT})$ film. 


\subsection{Spectroscopic Properties of PInc, P(Inc-co-bT), and PbT Films}

Figure 7a-c showed the absorption spectra and photoimages of PInc, $\mathrm{P}($ Inc-co-bT), and $\mathrm{PbT}$ films coated on ITO glass substrate at various potentials in $0.2 \mathrm{M} \mathrm{LiClO}_{4} /(\mathrm{PC}+\mathrm{ACN})$ solution. The $\pi-\pi^{*}$ and $\mathrm{n}-\pi^{*}$ transition peak of PInc and PbT films in the neutral state located at around 350 and $450 \mathrm{~nm}$, respectively. However, the corresponding transition peak of $\mathrm{P}$ (Inc-co-bT) film located at about $395 \mathrm{~nm}$ (Figure $7 \mathrm{~b}$ ), the transition peak of $\mathrm{P}(\mathrm{Inc}-\mathrm{co}-\mathrm{bT})$ film shifted bathochromically compared to that of PInc film but shifted hypsochromically compared to that of PbT film. The absorption peaks of PInc film at $350 \mathrm{~nm}, \mathrm{PbT}$ film at $700 \mathrm{~nm}$, and P(Inc-co-bT) film at $395 \mathrm{~nm}$ decreased gradually when the potentials grew up, meanwhile, new absorption bands of PInc film at $750 \mathrm{~nm}$, PbT film at $450 \mathrm{~nm}$, and $\mathrm{P}(\mathrm{Inc}-\mathrm{co}-\mathrm{bT})$ film at $1020 \mathrm{~nm}$ emerged gradually, implying the generation of charge carriers [27].
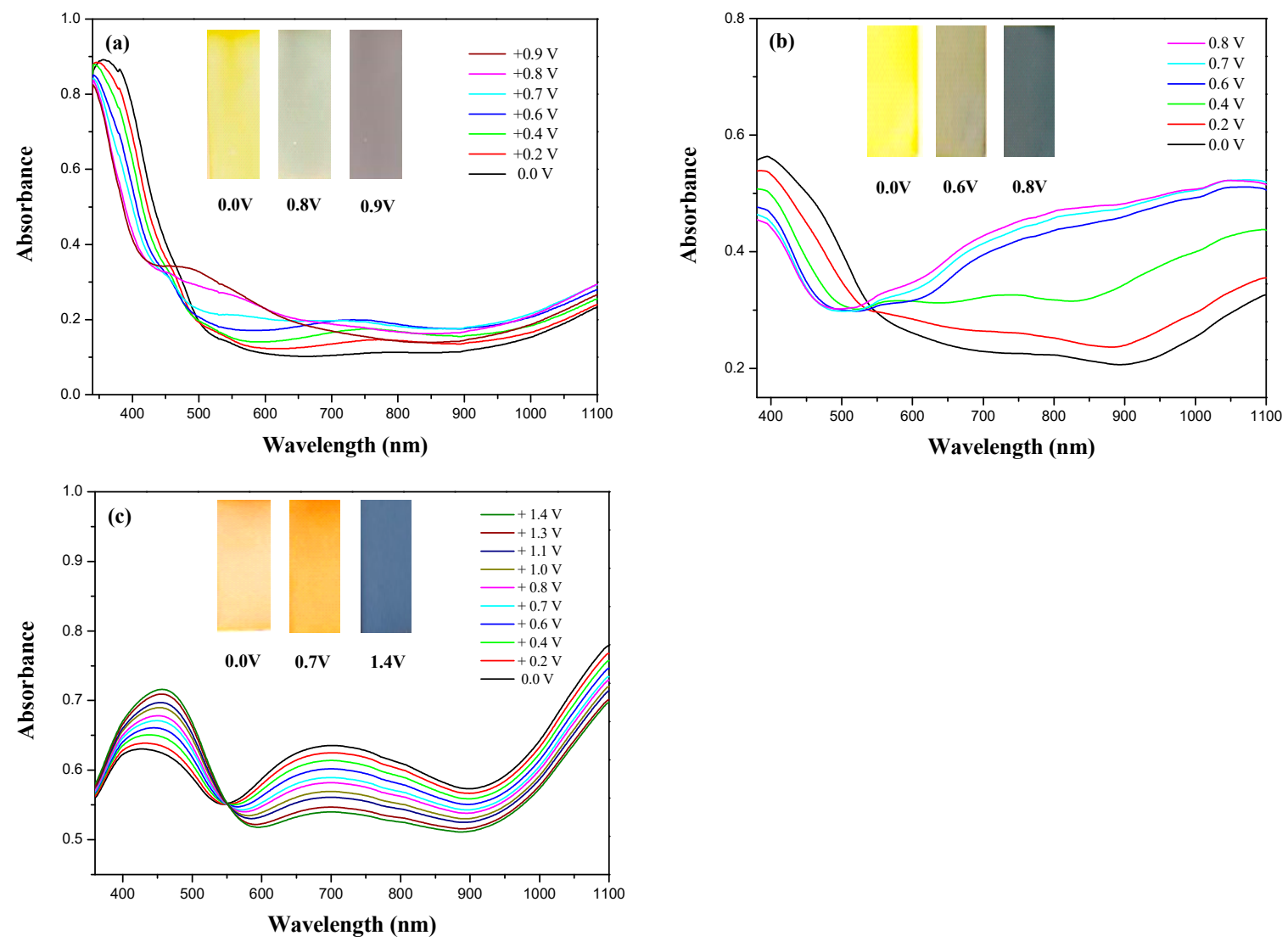

Figure 7. UV-Visible spectra of (a) PInc, (b) P(Inc-co-bT), and (c) PbT on ITO in PC + ACN solution containing $0.2 \mathrm{M} \mathrm{LiClO}_{4}$.

The PInc film was light yellow $(0.0 \mathrm{~V})$ in the neutral state, yellowish grey $(+0.8 \mathrm{~V})$ in the intermediate state, and purple $(+0.9 \mathrm{~V})$ in the oxidized state. The PbT film was light orange, dark orange, and dark blue at $0.0,+0.7$, and $+1.4 \mathrm{~V}$, respectively. Their corresponding $\mathrm{P}($ Inc-co-bT) copolymer film revealed light yellow, yellowish green, and bluish grey at $0.0,+0.6$, and $+0.8 \mathrm{~V}$, respectively. The colors of $\mathrm{P}(\mathrm{Inc}-\mathrm{co}-\mathrm{bT})$ film are different to those of PInc and $\mathrm{PbT}$ films during the doping process.

\subsection{Electrochemical Switching of PInc, P(Inc-co-bT), and PbT Films}

Kinetic studies of PInc, $\mathrm{P}\left(\right.$ Inc-co-bT), and PbT films in $0.2 \mathrm{M} \mathrm{LiClO}_{4} /(\mathrm{PC}+\mathrm{ACN})$ solution were monitored by increasing and decreasing of transmittance with respect to time between 0.0 and $+0.8 \mathrm{~V}$ (vs. $\mathrm{Ag} / \mathrm{AgNO}_{3}$ ) with a residence time of $10 \mathrm{~s}$.

As shown in Figure 8 and Table 2, the $\Delta T$ of PInc, $\mathrm{P}($ Inc-co-bT), and PbT films at the wavelength of absorption maxima are $17.8 \%$ at $510 \mathrm{~nm}, 30.2 \%$ at $890 \mathrm{~nm}$, and $27.0 \%$ at $470 \mathrm{~nm}$, respectively, in $0.2 \mathrm{M}$ 
$\mathrm{LiClO}_{4} /(\mathrm{PC}+\mathrm{ACN})$ solution. $\mathrm{P}($ Inc-co-bT) film shows higher $\Delta T$ than those of PInc and PbT films, implying the copolymer prepared using Inc. and $\mathrm{bT}$ monomers gave rise to significant charge carrier band than those of PInc and PbT homopolymer films. Response time was defined as the time required for achieving $90 \%$ of the desired response. The coloring response time $\left(\tau_{c}\right)$ and bleaching response time $\left(\tau_{\mathrm{b}}\right)$ at the 2 nd cycle were measured as 4.0 and $6.5 \mathrm{~s}$ for PInc film, 3.5 and $5.0 \mathrm{~s}$ for P(Inc-co-bT) film, and 3.0 and $5.2 \mathrm{~s}$ for PbT film, respectively.
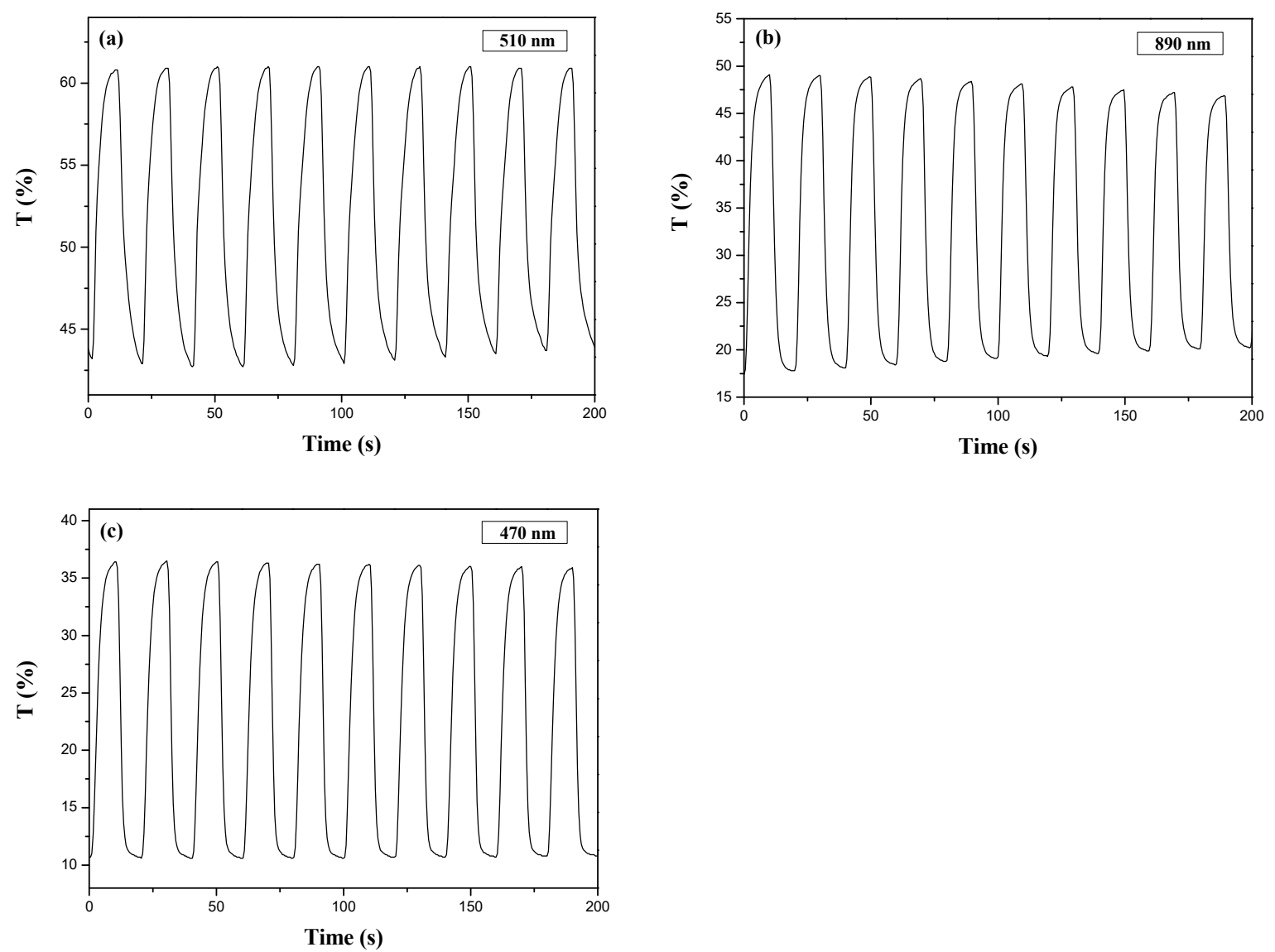

Figure 8. Transmittance variations of (a) PInc, (b) P(Inc-co-bT), and (c) PbT electrodes in PC+ACN solution containing $0.2 \mathrm{M} \mathrm{LiClO}_{4}$ between $0.0 \mathrm{~V}$ and $+0.8 \mathrm{~V}$ with a residence time of $10 \mathrm{~s}$.

Table 2. Optical and electrochemical properties investigated at the selected applied wavelength for the electrodes.

\begin{tabular}{cccccccccc}
\hline Polymer Electrodes & $\boldsymbol{\lambda} \mathbf{( n m )})^{\mathbf{a}}$ & $\boldsymbol{T}_{\mathbf{o x}}$ & $\boldsymbol{T}_{\text {red }}$ & $\boldsymbol{\Delta} \boldsymbol{T}$ & $\boldsymbol{\Delta O D}$ & $\boldsymbol{Q}_{\mathbf{d}}\left(\mathbf{m C} \mathbf{c m}^{-\mathbf{2}}\right)$ & $\boldsymbol{\eta}\left(\mathbf{c m}^{\mathbf{2}} \mathbf{C}^{-\mathbf{1}}\right)$ & $\boldsymbol{\tau}_{\mathbf{c}}(\mathbf{s})$ & $\boldsymbol{\tau}_{\mathbf{b}}(\mathbf{s})$ \\
\hline PInc & 510 & 43.4 & 61.8 & 17.8 & 0.153 & 3.73 & 41 & 4.0 & 6.5 \\
P(Inc-co-bT) & 890 & 18.0 & 48.2 & 30.2 & 0.428 & 3.80 & 112 & 3.5 & 5.0 \\
PbT & 470 & 11.0 & 38.0 & 27.0 & 0.538 & 4.80 & 113 & 3.0 & 5.2 \\
\hline \multicolumn{7}{c}{ a The selected applied wavelength for the electrodes. }
\end{tabular}

The coloration efficiency $(\eta)$ of PInc, $\mathrm{P}($ Inc-co-bT), and PbT films can be calculated using the following formulas [28]:

$$
\begin{gathered}
\eta=\Delta \mathrm{OD} / Q_{\mathrm{d}} \\
\Delta \mathrm{OD}=\log \left(T_{\mathrm{b}} / T_{\mathrm{c}}\right)
\end{gathered}
$$

where $\Delta \mathrm{OD}$ indicates the change of the optical density at a specific wavelength, $Q_{\mathrm{d}}$ is the charge density of electrochromic electrodes, and $T_{\mathrm{b}}$ and $T_{\mathrm{c}}$ represent the transmittance of the bleaching and 
coloring states, respectively. The $\eta$ of PInc, $\mathrm{P}\left(\right.$ Inc-co-bT), and PbT films are $41 \mathrm{~cm}^{2} \mathrm{C}^{-1}$ at $510 \mathrm{~nm}$, $112 \mathrm{~cm}^{2} \mathrm{C}^{-1}$ at $890 \mathrm{~nm}$, and $113 \mathrm{~cm}^{2} \mathrm{C}^{-1}$ at $470 \mathrm{~nm}$, respectively.

\subsection{Spectroelectrochemistry of ECDs}

Figure 9a-c showed the spectroelectrochemical spectra of dual type PInc/PMMA-PC-ACN-LiClO 4 / PEDOT-PSS, P(Inc-co-bT)/PMMA-PC-ACN-LiClO 4 /PEDOT-PSS, and PbT/PMMA-PC-ACN-LiClO 4 / PEDOT-PSS ECDs at various potentials, PInc/PMMA-PC-ACN-LiClO 4 /PEDOT-PSS ECD shows a shoulder at around $370 \mathrm{~nm}$ at $0.0-0.6 \mathrm{~V}$, this can be attributed to the $\pi-\pi^{*}$ transition peak of PInc film in its neutral state.
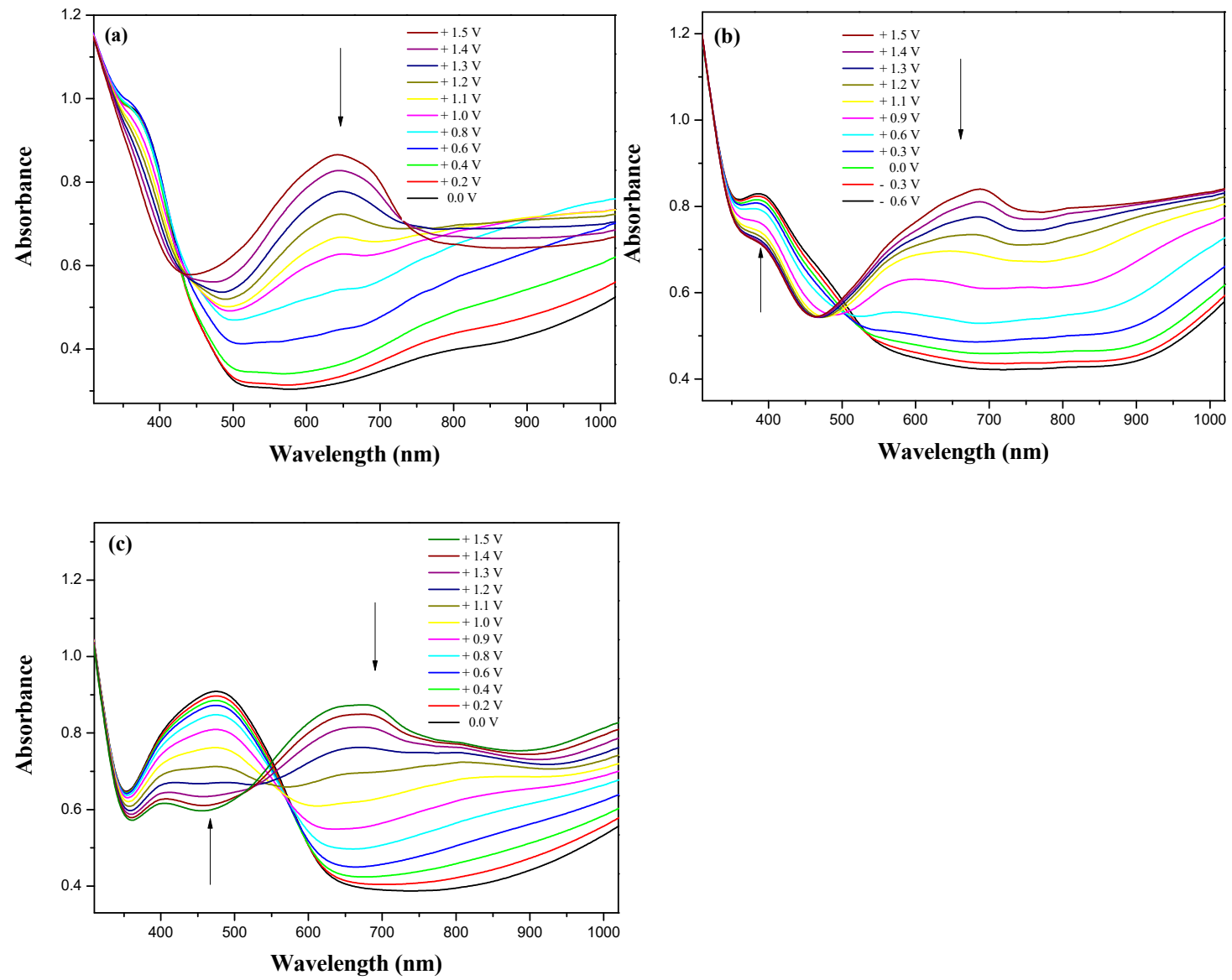

Figure 9. UV-Visible spectra of (a) PInc/PMMA-PC-ACN-LiClO $4 /$ PEDOT-PSS; (b) P(Inc-co-bT)/ PMMA-PC-ACN-LiClO 4 /PEDOT-PSS; and (c) PbT/PMMA-PC-ACN-LiClO 4 /PEDOT-PSS ECDs.

In the situation, PEDOT-PSS was transparent in its oxidation state, and PInc film was light yellow at $0.0 \mathrm{~V}$. Under similar condition, $\mathrm{P}(\mathrm{Inc}-\mathrm{co}-\mathrm{bT}) / \mathrm{PMMA}-\mathrm{PC}-\mathrm{ACN}-\mathrm{LiClO}_{4} / \mathrm{PEDOT}-\mathrm{PSS}$ ECD shows a peak at around $380 \mathrm{~nm}$ at $0.0 \mathrm{~V}$, the absorption peak for $\mathrm{P}$ (Inc-co-bT) film diminished and a new absorption band at $700 \mathrm{~nm}$ appeared at $+1.4 \mathrm{~V}$, the P(Inc-co-bT)/PMMA-PC-ACN-LiClO $4 / \mathrm{PEDOT}_{4} \mathrm{PSS}$ ECD was indigo at $+1.4 \mathrm{~V}$ as shown in Figure 1. PInc/PMMA-PC-ACN-LiClO $4 /$ PEDOT-PSS ECD showed light orange and dark blue at 0.0 and $+1.5 \mathrm{~V}$, respectively.

The transmittance-time profiles of PInc/PMMA-PC-ACN-LiClO 4 /PEDOT-PSS, P(Inc-co-bT)/ PMMA-PC-ACN-LiClO 4 /PEDOT-PSS, and PbT/PMMA-PC-ACN-LiClO 4 /PEDOT-PSS ECDs were shown in Figure 10 and the $\Delta T, \Delta \mathrm{OD}, \eta, \tau_{\mathrm{c}}$, and $\tau_{\mathrm{b}}$ of these ECDs are listed in Table 3. 

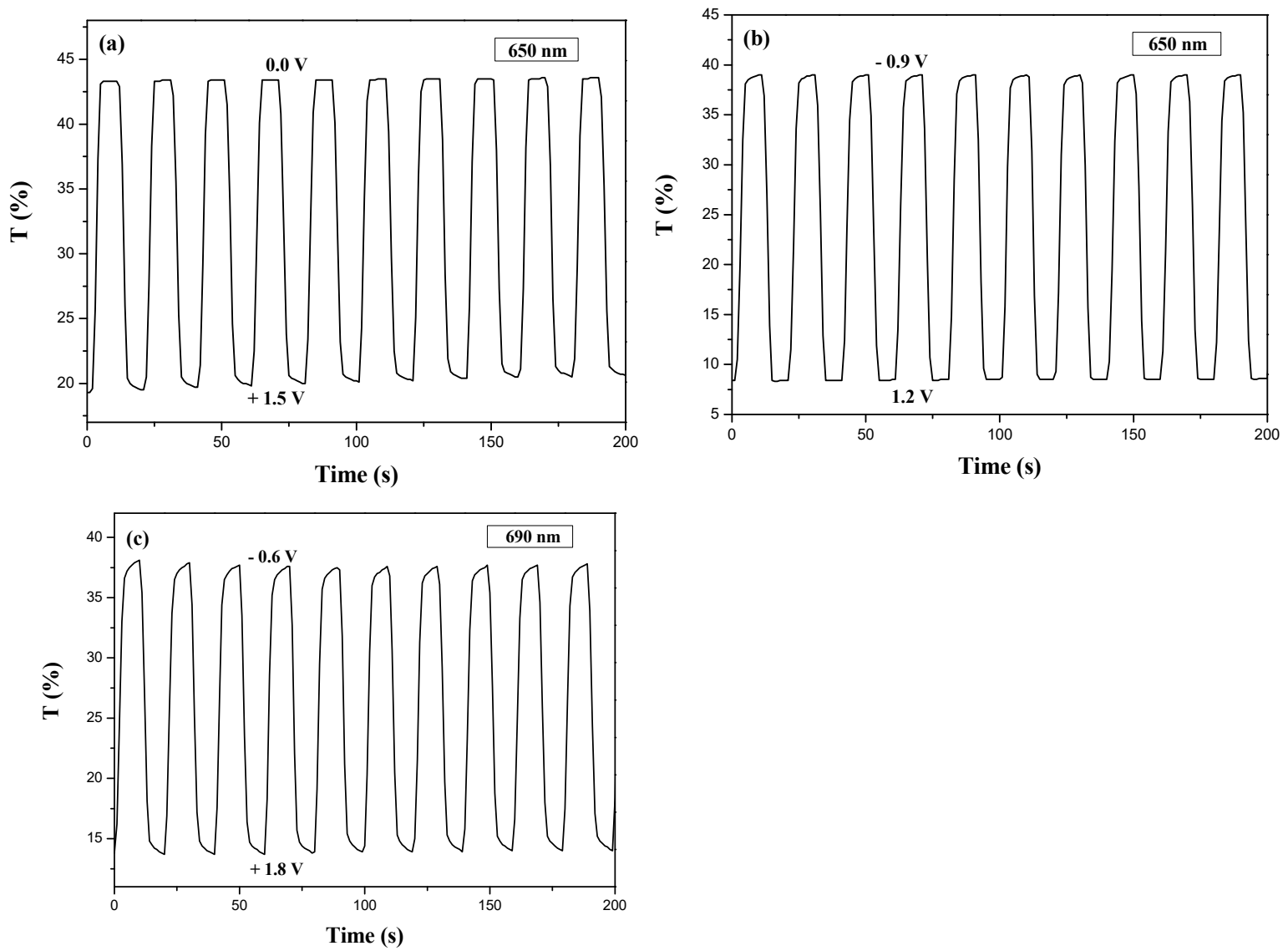

Figure 10. Transmittance variations of (a) PInc/PMMA-PC-ACN-LiClO 4 /PEDOT-PSS; (b) P(Inc-co-bT)/ PMMA-PC-ACN-LiClO 4 /PEDOT-PSS; and (c) PbT/PMMA-PC-ACN-LiClO 4 /PEDOT-PSS ECDs with a residence time of $10 \mathrm{~s}$.

Table 3. Optical and electrochemical properties investigated at the selected applied wavelength for the devices.

a The selected applied wavelength for the devices.

The $\Delta T \%$ of PInc/PMMA-PC-ACN-LiClO 4 / PEDOT-PSS, P(Inc-co-bT)/PMMA-PC-ACN-LiClO 4 / PEDOT-PSS, and PbT/PMMA-PC-ACN-LiClO $4 /$ PEDOT-PSS ECDs were $25 \%$ at $650 \mathrm{~nm}, 31 \%$ at $650 \mathrm{~nm}$, and $24.5 \%$ at $690 \mathrm{~nm}$, respectively. An ECD employed copolymer (P(Inc-co-bT)) as anodic layer showed higher $\Delta T$ than those of anodic homopolymers (PInc and $\mathrm{PbT}$ ). From another point of view, PInc/PMMA-PC-ACN-LiClO 4 /PEDOT-PSS ECD showed higher $\eta\left(416.7 \mathrm{~cm}^{2} \mathrm{C}^{-1}\right.$ at $650 \mathrm{~nm})$ than those of P(Inc-co-bT)/PMMA-PC-ACN-LiClO 4 /PEDOT-PSS $\left(320 \mathrm{~cm}^{2} \mathrm{C}^{-1}\right.$ at $\left.650 \mathrm{~nm}\right)$ and PbT/PMMA-PC-ACN-LiClO 4 /PEDOT-PSS $\left(266.1 \mathrm{~cm}^{2} \mathrm{C}^{-1}\right.$ at $\left.690 \mathrm{~nm}\right)$ ECDs. Furthermore, $\mathrm{P}(\mathrm{Inc}-\mathrm{co}-\mathrm{bT}) / \mathrm{PMMA}-\mathrm{PC}-\mathrm{ACN}-\mathrm{LiClO}_{4} / \mathrm{PEDOT}-\mathrm{PSS}$ ECD shows shorter $\tau_{\mathrm{c}}$ and $\tau_{\mathrm{b}}$ than those of PInc/ PMMA-PC-ACN-LiClO 4 /PEDOT-PSS and PbT/PMMA-PC-ACN-LiClO 4 /PEDOT-PSS ECDs, implying an ECD employed copolymer (P(Inc-co-bT)) as anodic layer changes color faster from the bleaching state to the coloring state than those of anodic homopolymers.

The comparisons of $\Delta T, \eta$ and $\tau$ with reported ECDs are shown in Table 4, P(Inc-co-bT)/ PEDOT-PSS ECD shows higher $\Delta T_{\max }$ than that reported for PInc/PProDOT-Et ${ }_{2}$ ECD [29], whereas the $\Delta T_{\max }$ of P(Inc-co-bT)/PEDOT-PSS ECD is lower than those of PIn/PEDOT [30] and P(Cz-co-CIn)/ 
PProDOT-Me 2 [31] ECDs. In the other hand, P(Inc-co-bT)/PEDOT-PSS ECD shows higher $\eta$ at $650 \mathrm{~nm}$ than that reported for PInc/PProDOT-Et ${ }_{2}$ [29] ECD, thereby allowing fast switching rates of $\mathrm{P}(\mathrm{Inc}-\mathrm{co}-\mathrm{bT}) /$ PEDOT-PSS ECD. In addition, the $\tau_{\mathrm{c}}$ of P(Inc-co-bT)/PEDOT-PSS ECD is shorter than those reported for PInc/PProDOT-Et ${ }_{2}$ [29], PIn/PEDOT [30], and P(Cz-co-CIn)/PProDOT-Me 2 [31] ECDs, which makes $\mathrm{P}($ Inc-co-bT)/PEDOT-PSS ECD desirable for electrochromic applications.

Table 4. Electrochemical optical contrast and coloration efficiencies of ECDs.

\begin{tabular}{cccccc}
\hline ECD Configuration & $\boldsymbol{\Delta} \boldsymbol{T}_{\max }(\mathbf{\%})$ & $\eta_{\max }\left(\mathbf{c m}^{\mathbf{2}} \mathbf{C}^{-\mathbf{1}}\right)$ & $\boldsymbol{\tau}_{\mathbf{c}}(\mathbf{s})$ & $\boldsymbol{\tau}_{\mathbf{b}}(\mathbf{s})$ & Ref. \\
\hline PInc/PProDOT-Et & $22.0(580 \mathrm{~nm})$ & 186 & 1.4 & 5.0 & {$[29]$} \\
PIn/PEDOT & $45.0(600 \mathrm{~nm})$ & 510 & 1.0 & 1.0 & {$[30]$} \\
P(Cz-co-CIn)/PProDOT-Me & $22.0(575 \mathrm{~nm})$ & 372.7 & 4.3 & 4.4 & {$[31]$} \\
P(Inc-co-bT)/PEDOT-PSS & $31.0(650 \mathrm{~nm})$ & 320.0 & 0.8 & 1.4 & This work \\
\hline
\end{tabular}

\subsection{Long-Term Stability and Optical Memory Effect of ECDs}

The long-term cycling stability of PInc/PMMA-PC-ACN-LiClO 4 /PEDOT-PSS, P(Inc-co-bT)/ PMMA-PC-ACN-LiClO 4 /PEDOT-PSS, and PbT/PMMA-PC-ACN-LiClO 4 /PEDOT-PSS ECDs were measured using cyclic voltammetry with a scan rate of $500 \mathrm{mV} \mathrm{s}^{-1}$. As shown in Figure 11, 98.1\%, 99.9\%, and $99.6 \%$ of activity was maintained after 500 cycles for PInc/PMMA-PC-ACN-LiClO $/$ PEDOT-PSS, P(Inc-co-bT)/PMMA-PC-ACN-LiClO 4 /PEDOT-PSS, and PbT/PMMA-PC-ACN-LiClO $4 /$ PEDOT-PSS ECDs, respectively, and $98.9 \%, 99.7 \%$, and $98.1 \%$ of activity was maintained after 1000 cycles for PInc/PMMA-PC-ACN-LiClO 4 /PEDOT-PSS, P(Inc-co-bT)/PMMA-PC-ACN-LiClO ${ }_{4} /$ PEDOT-PSS, and PbT/PMMA-PC-ACN-LiClO 4 /PEDOT-PSS ECDs, respectively, demonstrating PInc/ PMMA-PC-ACN-LiClO 4 /PEDOT-PSS, P(Inc-co-bT)/PMMA-PC-ACN-LiClO 4 /PEDOT-PSS, and PbT/ PMMA-PC-ACN-LiClO 4 /PEDOT-PSS ECDs exhibited an adequate long-term cycling stability.
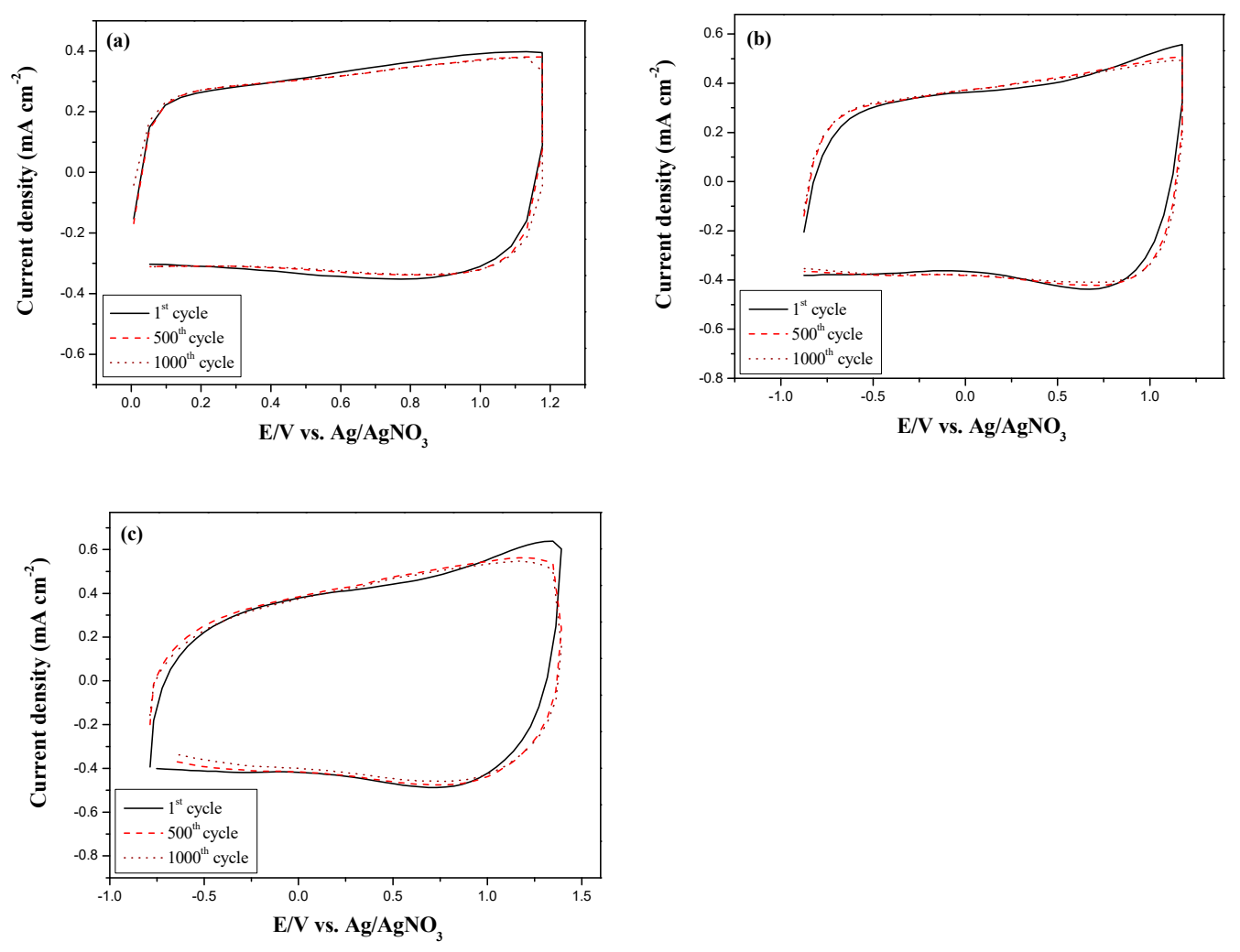

Figure 11. Cyclic voltammograms of (a) PInc/PMMA-PC-ACN-LiClO 4 /PEDOT-PSS; (b) P(Inc-co-bT)/ PMMA-PC-ACN-LiClO 4 /PEDOT-PSS; and (c) PbT/PMMA-PC-ACN-LiClO $4 /$ PEDOT-PSS ECDs as a function of repeated with a scan rate of $500 \mathrm{mV} \mathrm{s}^{-1}$ at 1st, 500th and 1000th cycles. 
The optical memory effect is a crucial character for ECDs [32]. The optical memory of PInc/ PMMA- PC-ACN-LiClO 4 /PEDOT-PSS, P(Inc-co-bT)/PMMA-PC-ACN-LiClO 4 /PEDOT-PSS, and PbT/ PMMA-PC-ACN-LiClO 4 /PEDOT-PSS ECDs was evaluated by giving potential for $1 \mathrm{~s}$ for each $100 \mathrm{~s}$ time interval. As shown in Figure 12b, the P(Inc-co-bT)/PMMA-PC-ACN-LiClO 4 / PEDOT-PSS ECD showed adequate optical memories in a neutral state of $\mathrm{P}(\mathrm{Inc}-\mathrm{co}-\mathrm{bT})$ film, the transmittance change of $\mathrm{P}(\mathrm{Inc}-\mathrm{co}-\mathrm{bT}) /$ PMMA-PC-ACN-LiClO 4 /PEDOT-PSS ECD is less than $1 \%$ in the reduced states of $\mathrm{P}($ Inc-co-bT) film.
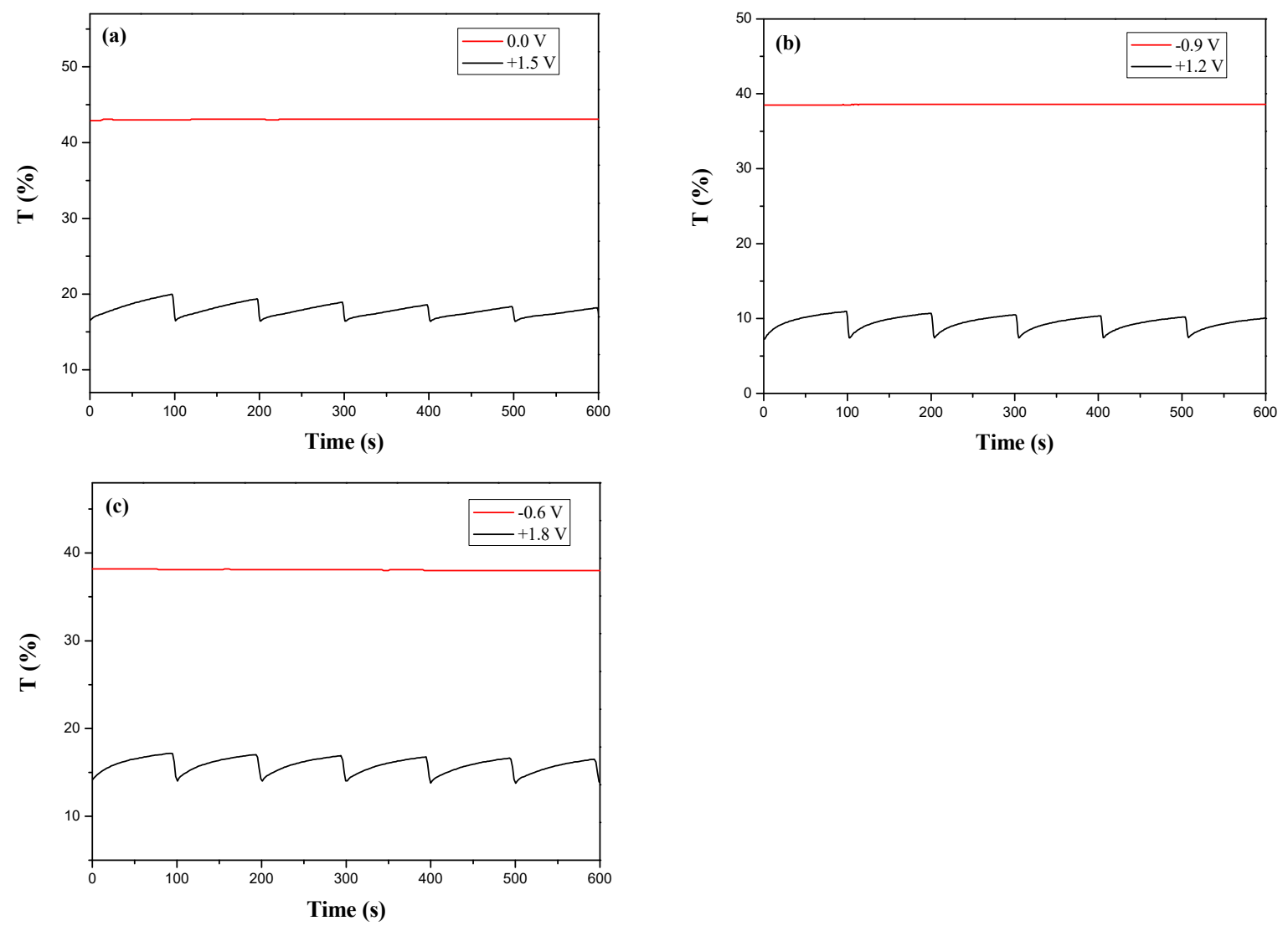

Figure 12. Open circuit stability of (a) PInc/PMMA-PC-ACN-LiClO 4 /PEDOT-PSS; (b) P(Inc-co-bT)/ PMMA-PC-ACN-LiClO 4 /PEDOT-PSS; and (c) PbT/PMMA-PC-ACN-LiClO 4 /PEDOT-PSS ECDs.

However, in the oxidized state of $\mathrm{P}(\mathrm{Inc}-\mathrm{co}-\mathrm{bT})$ film and in the reduced state of PEDOT-PSS film, the $\mathrm{P}(\mathrm{Inc}-\mathrm{co}-\mathrm{bT}) / \mathrm{PMMA}-\mathrm{PC}-\mathrm{ACN}-\mathrm{LiClO}_{4} / \mathrm{PEDOT}-\mathrm{PSS}$ ECD is less stable than that in reduced state of $\mathrm{P}(\mathrm{Inc}-\mathrm{co}-\mathrm{bT})$ film and oxidized state of PEDOT-PSS film, but the transmittance change of $\mathrm{P}($ Inc-co-bT)/PMMA-PC-ACN-LiClO $4 /$ PEDOT-PSS ECD is less than $5 \%$, the optical memory of $\mathrm{P}(\mathrm{Inc}-\mathrm{co}-\mathrm{bT}) / \mathrm{PMMA}-\mathrm{PC}-\mathrm{ACN}-\mathrm{LiClO}_{4} / \mathrm{PEDOT}-\mathrm{PSS} \mathrm{ECD}$ are compared to other reported polymer-based ECDs $[33,34]$, indicating $\mathrm{P}(\mathrm{Inc}-\mathrm{co}-\mathrm{bT}) / \mathrm{PMMA}-\mathrm{PC}-\mathrm{ACN}-\mathrm{LiClO}_{4} / \mathrm{PEDOT}-\mathrm{PSS}$ ECD shows adequate optical memory in bleaching and coloring states.

\section{Conclusions}

$\mathrm{P}($ Inc-co-bT) film was coated on ITO electrode using electrochemical polymerization. Spectroelectrochemical analysis of $\mathrm{P}(\mathrm{Inc}-\mathrm{co}-\mathrm{bT})$ film showed distinct electrochromic behaviors, it was light yellow, yellowish green, and bluish grey at $0.0,+0.6$, and $+0.8 \mathrm{~V}$, respectively. $\mathrm{P}$ (Inc-co-bT) film showed higher transmittance change $(\Delta T=30.2 \%)$ than those of PInc and PbT films. Electrochromic switching studies of anodic polymer films displayed that $\mathrm{P}(\mathrm{Inc}-\mathrm{co}-\mathrm{bT})$ film had shorter switching time than those of PInc and PbT films. On the other hand, spectroelectrochemical studies of dual-type complementary ECDs display that P(Inc-co-bT)/PMMA-PC-ACN-LiClO 4 /PEDOT-PSS ECD was light 
yellow and indigo at -1.0 and $+1.4 \mathrm{~V}$, respectively. The $\Delta T$ and coloration efficiency of $\mathrm{P}($ Inc-co-bT)/ PMMA-PC-ACN-LiClO 4 /PEDOT-PSS ECD were $31 \%$ and $320 \mathrm{~cm}^{2} \mathrm{C}^{-1}$, respectively, at $650 \mathrm{~nm}$. Long-term cycling stability testing of ECDs confirmed that $\mathrm{P}(\mathrm{Inc}-\mathrm{co}-\mathrm{bT}) / \mathrm{PMMA}-\mathrm{PC}-\mathrm{ACN}-\mathrm{LiClO}_{4} /$ PEDOT-PSS ECD exhibited better stability than those of PInc/PMMA-PC-ACN-LiClO 4 /PEDOT-PSS and PbT/PMMA-PC-ACN-LiClO 4 /PEDOT-PSS ECDs.

Acknowledgments: The authors would like to thank the Ministry of Science and Technology (MOST) of Taiwan for financially supporting this project.

Author Contributions: Chung-Wen Kuo conceived the research topic. Shu-Chien Fan and Tzi-yi Wu implemented the experiments. Chung-Wen Kuo, Tzi-Yi Wu, and Shu-Chien Fan analyzed the electrochromic properties.

Conflicts of Interest: The authors declare no conflict of interest.

\section{References}

1. Beaujuge, P.M.; Reynolds, J.R. Color control in $\pi$-conjugated organic polymers for use in electrochromic devices. Chem. Rev. 2010, 110, 268-320. [CrossRef] [PubMed]

2. Wang, R.; Yan, X.; Yang, X.; Wang, Y.; Li, H.; Sheng, C. Long lived photoexcitation dynamics in $\pi$-conjugated polymer/PbS quantum dot blended films for photovoltaic application. Polymers 2017, 9, 352. [CrossRef]

3. Seshadri, V.; Padilla, J.; Bircan, H.; Radmard, B.; Draper, R.; Wood, M.; Otero, T.F.; Sotzing, G.A. Optimization, preparation, and electrical short evaluation for $30 \mathrm{~cm}^{2}$ active area dual conjugated polymer electrochromic windows. Org. Electron. 2007, 8, 367-381. [CrossRef]

4. Kuo, C.-W.; Lee, P.-Y. Electrosynthesis of copolymers based on 1,3,5-tris( $N$-carbazolyl)benzene and 2,2'-bithiophene and their applications in electrochromic devices. Polymers 2017, 9, 518. [CrossRef]

5. Hsiao, S.H.; Lin, S.W. The electrochemical fabrication of electroactive polymer films from diamide- or diimide-cored $\mathrm{N}$-phenylcarbazole dendrons for electrochromic applications. J. Mater. Chem. C 2016, 4 , 1271-1280. [CrossRef]

6. Wu, T.Y.; Sheu, R.B.; Chen, Y. Synthesis, optically acid-sensory and electrochemical properties of novel polyoxadiazole derivatives. Macromolecules 2004, 37, 725-733. [CrossRef]

7. Wu, T.Y.; Chen, Y. Poly(phenylene vinylene)-based copolymers containing 3,7-phenothiazylene and 2,6-pyridylene chromophores: Fluorescence sensors for acids, metal ions, and oxidation. J. Polym. Sci. Part A Polym. Chem. 2004, 42, 1272-1284. [CrossRef]

8. Kuo, C.W.; Chen, S.J.; Chen, P.R.; Tsai, W.T.; Wu, T.Y. Doping process effect of polyaniline doped with poly(styrenesulfonic acid) supported platinum for methanol oxidation. J. Taiwan Inst. Chem. Eng. 2013, 44, 497-504. [CrossRef]

9. Wu, T.Y.; Chen, P.R.; Chen, H.R.; Kuo, C.W. Preparation of Pt/poly(aniline-co-orthanilic acid)s nanocomposites and their applications for electrocatalytic oxidation of methanol. J. Taiwan Inst. Chem. Eng. 2016, 58, 458-466. [CrossRef]

10. Wu, T.Y.; Kuo, C.W.; Chen, Y.L.; Chang, J.K. Copolymers based on indole-6-carboxylic acid and 3,4-ethylenedioxythiophene as platinum catalyst support for methanol oxidation. Catalysts 2015, 5, 1657-1672. [CrossRef]

11. Wu, T.Y.; Chen, Y. Synthesis and characterization of novel luminescent polymers with alternate phenothiazine and divinylbenzene units. J. Polym. Sci. Part A Polym. Chem. 2002, 40, 4452-4462. [CrossRef]

12. Al-Asbahi, B.A.; Haji Jumali, M.H.; AlSalhi, M.S. Enhanced Optoelectronic Properties of PFO/Fluorol 7GA Hybrid Light Emitting Diodes via Additions of $\mathrm{TiO}_{2}$ Nanoparticles. Polymers 2016, 8, 334. [CrossRef]

13. Wu, T.Y.; Chen, Y. Synthesis, optical and electrochemical properties of novel copolymers containing alternate 2,3-quinoxaline and hole-transporting units. J. Polym. Sci. Part A Polym. Chem. 2002, 40, 4570-4580. [CrossRef]

14. Lin, K.; Zhang, S.; Liu, H.; Zhao, Y.; Wang, Z.; Xu, J. Effects on the electrochemical and electrochromic properties of 3 linked polythiophene derivative by the introduction of polyacrylate. Int. J. Electrochem. Sci. 2015, 10, 7720-7731.

15. Ming, S.; Zhang, S.; Liu, H.; Zhao, Y.; Mo, D.; Xu, J. Methacrylate modified polythiophene: Electrochemistry and electrochromics. Int. J. Electrochem. Sci. 2015, 10, 6598-6609.

16. Soyleyici, S.; Karakus, M.; Ak, M. Transparent-blue colored dual type electrochromic device: Switchable glass application of conducting organic-inorganic hybrid carbazole polymer. J. Electrochem. Soc. 2016, 163, H679-H683. [CrossRef] 
17. Hsiao, S.-H.; Hsueh, J.-C. Electrochemical synthesis and electrochromic properties of new conjugated polycarbazoles from di(carbazol-9-yl)-substituted triphenylamine and $N$-phenylcarbazole derivatives. J. Electroanal. Chem. 2015, 758, 100-110. [CrossRef]

18. Yu, W.; Chen, J.; Fu, Y.; Xu, J.; Nie, G. Electrochromic property of a copolymer based on 5-cyanoindole and 3,4-ethylenedioxythiophene and its application in electrochromic devices. J. Electroanal. Chem. 2013, 700, 17-23. [CrossRef]

19. Wu, T.Y.; Li, W.B.; Kuo, C.W.; Chou, C.F.; Liao, J.W.; Chen, H.R.; Tseng, C.G. Study of poly(methyl methacrylate)-based gel electrolyte for electrochromic device. Int. J. Electrochem. Sci. 2013, 8, 10720-10732.

20. Hsiao, S.-H.; Lu, H.-Y. Electrosynthesis of aromatic poly(amide-amine) films from triphenylamine-based electroactive compounds for electrochromic applications. Polymers 2017, 9, 708. [CrossRef]

21. Krukiewicz, K.; Jarosz, T.; Herman, A.P.; Turczyn, R.; Boncel, S.; Zak, J.K. The effect of solvent on the synthesis and physicochemical properties of poly(3,4-ethylenedioxypyrrole). Synth. Met. 2016, 217, $231-236$. [CrossRef]

22. Wu, T.Y.; Chung, H.H. Applications of tris(4-(thiophen-2-yl)phenyl)amine- and dithienylpyrrole-based conjugated copolymers in high-contrast electrochromic devices. Polymers 2016, 8, 206. [CrossRef]

23. Kuo, C.W.; Chen, B.K.; Li, W.B.; Tseng, L.Y.; Wu, T.Y.; Tseng, C.G.; Chen, H.R.; Huang, Y.C. Effects of supporting electrolytes on spectroelectrochemical and electrochromic properties of polyaniline-poly(styrene sulfonic acid) and poly(ethylenedioxythiophene)-poly(styrene sulfonic acid)-based electrochromic device. J. Chin. Chem. Soc. 2014, 61, 563-570. [CrossRef]

24. Nie, G.; Zhang, Y.; Guo, Q.; Zhang, S. Label-free DNA detection based on a novel nanostructured conducting poly(indole-6-carboxylic acid) films. Sens. Actuators B Chem. 2009, 139, 592-597. [CrossRef]

25. Yıldırım, M.; Kaya, I.; Aydın, A. Azomethine coupled fluorene-thiophene-pyrrole based copolymers: Electrochromic applications. React. Funct. Polym. 2013, 73, 1167-1174. [CrossRef]

26. Hacioglu, S.O.; Yiğit, D.; Ermis, E.; Soylemez, S.; Güllü, M.; Toppare, L. Syntheses and electrochemical characterization of low oxidation potential nitrogen analogs of pedot as electrochromic materials. J. Electrochem. Soc. 2016, 163, E293-E299. [CrossRef]

27. Carbas, B.B.; Kivrak, A.; Teke, E.; Zora, M.; Önal, A.M. Electrochemical polymerization of a new low-voltage oxidized thienylenepyrrole derivative and its electrochromic device application. J. Electroanal. Chem. 2014, 729, 15-20. [CrossRef]

28. Chang, K.H.; Wang, H.P.; Wu, T.Y.; Sun, I.W. Optical and electrochromic characterizations of four 2,5-dithienylpyrrole-based conducting polymer films. Electrochim. Acta 2014, 119, 225-235. [CrossRef]

29. Kuo, C.W.; Wu, T.Y.; Huang, M.W. Electrochromic characterizations of copolymers based on 4,4'-bis( $N$-carbazolyl)-1,1'-biphenyl and indole-6-carboxylic acid and their applications in electrochromic devices. J. Taiwan Inst. Chem. Eng. 2016, 68, 481-488. [CrossRef]

30. Nie, G.; Zhou, L.; Guo, Q.; Zhang, S. A new electrochromic material from an indole derivative and its application in high-quality electrochromic devices. Electrochem. Commun. 2010, 12, 160-163. [CrossRef]

31. Kuo, C.W.; Hsieh, T.H.; Hsieh, C.K.; Liao, J.W.; Wu, T.Y. Electrosynthesis and characterization of four electrochromic polymers based on carbazole and indole-6-carboxylic acid and their applications in high-contrast electrochromic devices. J. Electrochem. Soc. 2014, 161, D782-D790. [CrossRef]

32. Kuo, C.W.; Wu, T.L.; Lin, Y.C.; Chang, J.K.; Chen, H.R.; Wu, T.Y. Copolymers based on 1,3-bis(carbazol-9-yl)benzene and three 3,4-ethylenedioxythiophene derivatives as potential anodically coloring copolymers in high-contrast electrochromic devices. Polymers 2016, 8, 368. [CrossRef]

33. Wu, T.Y.; Li, J.L. Electrochemical synthesis, optical, electrochemical and electrochromic characterizations of indene and 1,2,5-thiadiazole-based poly(2,5-dithienylpyrrole) derivatives. RSC Adv. 2016, 6, 15988-15998. [CrossRef]

34. Su, Y.S.; Chang, J.C.; Wu, T.Y. Applications of three dithienylpyrroles-based electrochromic polymers in high-contrast electrochromic devices. Polymers 2017, 9, 114. [CrossRef]

(C) 2018 by the authors. Licensee MDPI, Basel, Switzerland. This article is an open access article distributed under the terms and conditions of the Creative Commons Attribution (CC BY) license (http://creativecommons.org/licenses/by/4.0/). 